\title{
Diurnal blood pressure pattern and development of prehypertension or hypertension in young adults: the CARDIA study
}

\author{
Anthony J. Viera ${ }^{1}$, Sha Zhu ${ }^{2}$, Alan L. Hinderliter ${ }^{3}$, Daichi Shimbo ${ }^{4}$, Sharina D. Person ${ }^{2}$, \\ and David R. Jacobs Jr. ${ }^{5}$ \\ ${ }^{1}$ Department of Family Medicine, University of North Carolina at Chapel Hill \\ ${ }^{2}$ Department of Medicine, Division of Preventive Medicine, University of Alabama at Birmingham \\ ${ }^{3}$ Department of Medicine, Division of Cardiology, University of North Carolina at Chapel Hill \\ ${ }^{4}$ Department of Medicine, Columbia University Medical Center, New York, NY \\ ${ }^{5}$ Division of Epidemiology and Community Health, School of Public Health, University of \\ Minnesota
}

\begin{abstract}
Nondippers (people whose sleep systolic blood pressure (SBP) fails to decrease $>10 \%$ from daytime SBP) have increased risk of cardiovascular disease. The prevalence of nondipping in younger adults has not been well-studied, nor has its value for predicting hypertension. We examined the prevalence of nondipping in a sub-study of the Coronary Artery Risk Development in Young Adults (CARDIA) Study. We used Cox regression to estimate the hazard ratio (HR) conferred by nondipping for incident prehypertension or hypertension (preHTN/HTN) over 15 years. Of the 264 non-hypertensive participants at baseline, 118 (45\%) were nondippers. Blacks were more likely than Whites to be nondippers $(52 \%$ vs $33 \%, \mathrm{p}=0.004)$. The incidence rate of preHTN/HTN was 29.2/1000 person-years among dippers and 36.2/1000 person-years among nondippers. Compared to those in the lowest quartile of nighttime to daytime SBP, those in the highest quartile were more likely to develop preHTN/HTN (HR 1.61; $\mathrm{p}=0.06$ ), but this relationship was attenuated after adjustment (HR 1.34; $\mathrm{p}=0.27$ ). Our results demonstrate that nondipping is common in young, nonhypertensive adults, and is more common in Blacks than Whites. Nondipping might predate a meaningful clinically detected increase in BP in some people, but more research in larger study samples is needed.
\end{abstract}

\section{Keywords}

diurnal blood pressure; blood pressure dipping; hypertension

\footnotetext{
(c) 2010 American Society of Hypertension. Published by Elsevier Inc. All rights reserved.

Corresponding Author: Anthony J. Viera, MD, MPH, Assistant Professor, Department of Family Medicine, University of North Carolina at Chapel Hill, 590 Manning Drive, CB 7595, Chapel Hill, NC 27599, Phone (919) 966-0758, anthony_viera@ med.unc.edu. Publisher's Disclaimer: This is a PDF file of an unedited manuscript that has been accepted for publication. As a service to our customers we are providing this early version of the manuscript. The manuscript will undergo copyediting, typesetting, and review of the resulting proof before it is published in its final citable form. Please note that during the production process errors may be discovered which could affect the content, and all legal disclaimers that apply to the journal pertain.

Conflicts of Interest to Disclose: None
} 


\section{Introduction}

Over the last two decades, through the use of 24-hour ambulatory blood pressure monitoring, the importance of the diurnal blood pressure (BP) pattern has been more clearly elucidated. $1^{-7}$ Normally during sleep, BP decreases ("dips") more than $10 \%$ from daytime baseline BP. Individuals who do not exhibit this $>10 \%$ decrease have been referred to as nondippers. In patients with hypertension, nondipping has been shown to be associated with target organ damage and cardiovascular events. $1^{-6}$ In the general population, nondipping may be a risk factor for cardiovascular disease mortality independent of the overall BP during a 24-hour period.6 In one study of normotensive individuals (defined as clinic BP $<140 / 90 \mathrm{~mm} \mathrm{Hg}$ and 24-hour ambulatory BP average $<125 / 80 \mathrm{~mm} \mathrm{Hg}$ ), the nondipping pattern was shown to be associated with cardiac hypertrophy and remodeling.7

Not only does the nondipping pattern appear to be associated with an increased cardiovascular risk, but it is also common. Nondipping was recently shown to be present in approximately $40 \%$ of untreated hypertensives and more than $50 \%$ of treated hypertensives. ${ }^{8}$ The nondipping pattern also occurs in approximately $30 \%$ of older normotensive adults. ${ }^{7}$ However, the prevalence of the nondipping pattern in younger adults who are not hypertensive has not been well studied. Also not known is whether nondipping in young normotensive adults is predictive of future hypertension.

In physiological terms, the sympathetic nervous system plays an important role in the pathogenesis of hypertension and of cardiovascular disease. ${ }^{9}$ Autonomic imbalances (increased sympathetic tone and decreased parasympathetic tone) lead to increased heart rate, vasoconstriction, and increased BP. Elevated BP, in turn, leads to an alteration in arterial and aortic baroreceptor function, and loss of sympathetic inhibition is one of the mechanisms responsible for failure of BP to dip during sleep. ${ }^{10}$ It is possible that nondipping is an early change in a person's BP pattern, and the loss of nocturnal BP reduction may predate the onset of clinical hypertension.

The objectives of this study were (1) to estimate the prevalence of the nondipping BP pattern among young, non-hypertensive Black and White adults, and (2) to examine whether a nondipping BP pattern among young adults is associated with the development of prehypertension or hypertension. We hypothesized that young adults with a nondipping pattern would be more likely to develop prehypertension or hypertension than those with a normal dipping pattern.

\section{Methods}

\section{Overall Design}

The Coronary Artery Risk Development in Young Adults Study (CARDIA) is an ongoing, prospective, epidemiologic study, conducted at four sites throughout the United States. A detailed description of the study design and recruitment methods can be found in an earlier publication. ${ }^{11}$ The data presented in this paper are from a subgroup of individuals who participated in an ambulatory BP monitoring substudy in 1990 (year 5 of CARDIA) and had ongoing follow-up visits. The CARDIA study and this substudy were approved by the appropriate Institutional Review Boards (IRBs), and informed consent was obtained from each study participant. The plans for this secondary analysis were also submitted to the University of North Carolina's Office of Human Research Ethics and deemed exempt from further review. 


\section{Study Participants}

As previously described, ${ }^{12}$ for feasibility reasons, ambulatory BP monitoring measurements were performed at only one of the CARDIA study sites (Birmingham, AL). A list of 100 people randomly chosen from each of the four race/gender subgroups (Black and White men and women) was generated at the CARDIA Coordinating Center. After excluding individuals whose jobs would make ambulatory BP monitoring difficult (e.g., truck drivers, delivery people), a total of 316 people (147 men and 169 women; 112 Whites and 204 Blacks) participated in the ambulatory BP monitoring sub-study.

\section{Ambulatory Blood Pressure Monitoring}

Ambulatory blood pressure was monitored over a 24 hour period using a Suntech Accutracker II (Suntech Medical, Morrisville, NC), using an appropriately sized cuff which was inflated approximately every 20 minutes. ${ }^{13}$ To reduce anticipation effects, the inflation schedule was variable. If any value outside preset limits (systolic $\geq 220$ or $\leq 80 \mathrm{~mm} \mathrm{Hg}$; diastolic $\geq 130$ or $\leq 40 \mathrm{~mm} \mathrm{Hg}$ ) was detected during a recording, that measurement was rejected and another measurement was immediately made. In addition, a change of $50 \mathrm{~mm}$ $\mathrm{Hg}$ in systolic pressure, of $40 \mathrm{~mm} \mathrm{Hg}$ in diastolic pressure, or of $50 \mathrm{~mm} \mathrm{Hg}$ in pulse pressure also triggered a rejection and a new reading. Daytime was defined as the period between 0700 and 2359, and we required a minimum of 14 adequate measurements. Nighttime was defined as the period between 0000 and 0659 , and we required a minimum of six adequate measurements. Blood pressure dipping at baseline was quantified as the ratio of mean nighttime systolic BP to mean daytime systolic BP. Nondipping pattern was defined as a ratio $\geq 0.90$.

\section{Clinic Blood Pressure Measurements}

Prior to study visits, participants were asked to refrain from smoking and heavy physical activity. At each visit, after five minutes of rest, three seated right arm BP measurements were recorded at one-minute intervals. Using an appropriately sized cuff, the first-phase and fifth-phase Korotkoff sounds were taken as the systolic and diastolic blood pressures, respectively, using a random zero sphygmomanometer. Individuals with hypertension at baseline (defined as on BP-lowering meds at CARDIA year 5) or CARDIA visit 5 clinic BP average (based on second and third readings) of either systolic $\geq 140 \mathrm{~mm} \mathrm{Hg}$ or diastolic $\geq 90 \mathrm{~mm} \mathrm{Hg}$ were excluded from this analysis, leaving 264 "at-risk" people in the final study sample. At the 15-year follow-up visit (CARDIA year 20), clinic BP was measured using a digital oscillometric monitor (Omron HEM-907XL; Online Fitness, Santa Monica, California) rather than a random zero sphygmomanometer. A calibration study was performed at year 20 in approximately 900 participants, and we used the formulae calibrated year 20 systolic blood pressure $=3.74+0.96 *$ observed Omron systolic blood pressure and calibrated year 20 diastolic blood pressure $=1.30+0.97 *$ observed Omron systolic blood pressure.

\section{Covariates}

Education was determined by self report of highest grade level achieved. Body mass index (BMI) was calculated based on measured height and weight at the baseline visit. Diabetes mellitus was defined as a fasting glucose level $\geq 126 \mathrm{mg} / \mathrm{dL}$ or use of hypoglycemic agents at baseline (CARDIA year 5). Family history of hypertension and smoking status were determined by self-report. Alcohol consumption was a continuous variable (ethanol intake, $\mathrm{mL}$ /day). Physical activity was assessed by the CARDIA physical activity questionnaire, which measured the self-reported frequency of participation in 13 different categories of recreational sports and exercise in the past 12 months. ${ }^{14}$ Physical activity scores were computed by multiplying the frequency of participation by the intensity of activity and 
reported as "exercise units." Energy expenditure could not be computed because duration of activity was not queried.

\section{Analysis}

Our exposure variable was nondipping pattern based on ambulatory BP monitoring performed in 1990. Our outcome was clinical worsening of BP category-from optimal BP to incident prehypertension or hypertension, or from prehypertension to incident hypertension. Hypertension was defined as a clinic visit average (of second and third readings) systolic $\mathrm{BP} \geq 140 \mathrm{mmHg}$ or average diastolic $\mathrm{BP} \geq 90 \mathrm{mmHg}$ or interval initiation of an antihypertensive medication. Prehypertension was defined as a clinic visit BP average (of second and third readings) systolic BP $\geq 120 \mathrm{~mm} \mathrm{Hg}$ or average diastolic BP $\geq 80 \mathrm{~mm}$ $\mathrm{Hg}$ with neither reading $\geq 140 / 90 \mathrm{~mm} \mathrm{Hg}$. Time of follow-up was 15 years. In the survival analyses, a participant was censored when a change in BP category was detected (optimal $\mathrm{BP}$, defined as systolic $\mathrm{BP}<120 \mathrm{~mm} \mathrm{Hg}$ and diastolic $\mathrm{BP}<80 \mathrm{~mm} \mathrm{Hg}$, to prehypertension, prehypertension to hypertension, or optimal BP to hypertension). A categorization change from optimal BP to hypertension was counted as a change from optimal to hypertension whether or not the person had $\mathrm{BP}$ in the prehypertension range in the interim.

We calculated the crude hazard ratio and then performed a series of Cox regression analyses. In the first model, we adjusted only for race. In a second model, we adjusted for race and BMI. In a fully adjusted model, we included baseline clinic systolic BP as well as age, sex, race/ethnicity, BMI, diabetes mellitus, physical activity, family history of hypertension, alcohol consumption, and cigarette smoking. ${ }^{15} \mathrm{We}$ also tested the significance of an interaction term of race and dipping status. We repeated the regression analyses using the ratio of nocturnal to daytime systolic $\mathrm{BP}$ as a categorical exposure based on quartiles as well as continuously.

\section{Results}

\section{Characteristics of Sample}

The mean age of participants at baseline was 30 years (Table 1). Forty five percent of participants were male, and 63\% were Black. Few had known diabetes, but half were overweight or obese. Among this study sample, $28 \%$ were current smokers at baseline. Overall, there were 118 people (45\%) with a nondipping BP pattern. This percentage included 11 people whose BP was actually higher at night—so-called "reverse dippers". A total of 201 participants had optimal clinic BP at baseline. The remaining 63 participants had baseline clinic BP in the prehypertension range. Among those with optimal BP, $45 \%$ were nondippers, and among those with prehypertension, $44 \%$ were nondippers. Mean clinic BP among dippers and nondippers was similar at baseline, as was mean 24 hour average BP (Table 2). As expected, the mean nighttime BP was lower among the dippers (102/57 mm $\mathrm{Hg}$ vs $109 / 62 \mathrm{~mm} \mathrm{Hg}$ ). The associated BP changes from day to night reflect these differences. Interestingly, daytime BP average was slightly lower among nondippers (115/69 $\mathrm{mm} \mathrm{Hg}$ vs $118 / 70 \mathrm{~mm} \mathrm{Hg}$ ).

\section{Associations with Nondipping Status}

Of all characteristics examined, Black race and obesity were the only factors associated with nondipping status (Table 3). Among White participants, 33\% were nondippers/reverse dippers, while among Blacks, 52\% were nondippers/reverse dippers $(\mathrm{p}=0.004)$. Among normal weight or overweight participants, $41 \%$ in each category were nondippers/reverse dippers, but among obese participants, 57\% were nondippers/reverse dippers $(\mathrm{p}=0.07)$. 


\section{Incident Change in BP Category}

Over the 15 years of follow-up, there were 128 incident cases of clinical worsening of BP category (81 incident cases of hypertension and 47 incident cases of prehypertension) (Table 4). The incidence rate of change in clinical BP category was 29.2 per 1000 person-years among the dippers and 36.2 per 1000 person-years among the nondippers/reverse dippers for a hazard ratio of $1.33(\mathrm{p}=0.10)$. When adjusted for race, the association was mitigated (HR 1.22; $\mathrm{p}=0.27$ ). Additional adjustment for BMI further reduced the hazard ratio, but full adjustment with all covariates had little effect. The interaction of race and dipping status was not significant $(\mathrm{p}=0.37)$.

The ratio of baseline nighttime to daytime systolic BP ratio ranged from 0.736 to 1.19 . Compared to those in the lowest quartile of nighttime to daytime systolic BP, those in the highest quartile had a hazard ratio of $1.61(\mathrm{p}=0.06)$ for change in clinical BP category (Table 5 ). When adjusted for race, the association persisted in the hypothesized direction, but the magnitude of the association was reduced, and the near-statistical significance of highest to lowest quartile was mitigated (HR 1.43; p=0.17). Further adjustment for BMI also mitigated the association. A fully adjusted model differed little from the model adjusted only for race and BMI. In a Cox regression model examining baseline nighttime to daytime systolic BP ratio as a continuous variable, an increase of 0.05 in the ratio was associated with a 5\% increase (fully adjusted for covariates) in change in clinical BP category, but this was not significant (HR 1.05; $\mathrm{p}=0.48$ ).

\section{Discussion}

Among a sample of young adults with non-hypertensive blood pressure at baseline, we found that the nondipping pattern was common, present in 33\% of Whites and 52\% of Blacks. We also found that over a follow-up period of 15 years, nocturnal BP dipping status was positively, but not significantly (after adjustment) predictive of incident prehypertension or hypertension. The first implication of our findings is that many young otherwise healthy adults, though not hypertensive, may have a diurnal pattern of BP that places them at increased risk of target organ damage and increased cardiovascular disease mortality. The second implication is that nondipping in younger adults might predate hypertension, suggesting an early (pre-clinical) autonomic imbalance as a contributor. However, this finding needs confirmation in larger studies.

Since older age has repeatedly been a factor associated with the nondipping status, 6,8 we were somewhat surprised to find a high prevalence of the nondipping status in these young adults with non-hypertensive blood pressure. Previous studies have examined the prevalence of the nondipping pattern in various subgroups. Most such studies have been either in older people or in people with known hypertension. For example, one study of 183 unmedicated hypertensive patients showed the nondipping pattern to be present in $43 \%$ [16]. In a large international database containing ambulatory BP data on 7458 adults (mean age 57 years), nearly half of whom were taking BP-lowering drugs, $29 \%$ of participants were nondippers/ reverse dippers. 17 In a small study of older, normotensive Japanese adults, $34 \%$ were nondippers.7 A similar percentage (36\%) was seen in a study of 1542 adults with a mean age of 61 years and representative of the general population of older adults in Japan. 6 In more a recent cross-sectional study of 8383 untreated and 34,563 treated hypertensives, the nondipping pattern was present in $41 \%$ and 53\%, respectively.8 In the HARVEST study, among never-treated borderline to mild young hypertensives $(n=1062)$, nocturnal BP nondipping was present in 31\%.18 One study of a British population published in 1998 found that among 265 healthy, normotensive volunteers who underwent office and ambulatory BP measurements, $17 \%$ were nondippers. 19 Compared to the participants in our 
study, those in the British study were slightly older with a mean age of 39 years. Most importantly, however, all of the participants in that study were White.

In our study, Black race was the one factor significantly associated with nondipping status. Similar findings have been reported previously.20,21 In a study of 171 somewhat older (mean age of 53 years) Black and White normotensive and mildly hypertensive adults, 54\% of Blacks and $39 \%$ of Whites were nondippers. ${ }^{20}$ The observation of greater likelihood of nondipping among Blacks, even at earlier ages as shown in our study, is important and may partially explain the greater severity of hypertension-related target organ damage and resultant cardiovascular and renal disease in Blacks compared to Whites.22,23

We hypothesized that young non-hypertensive adults with a nondipping pattern would be more likely to develop a change in their clinical BP category, and our findings are suggestive that this is the case. Although two-side p-values were not significant, the findings are in the hypothesized direction, and one-sided p-values would have reached statistical significance in the crude analyses. These interesting results should therefore not be readily dismissed as due to chance, and further studies are warranted. There are few other studies to date that have examined this possibility. In the HARVEST study, mentioned above, nocturnal BP nondipping was a strong predictor of sustained clinic hypertension after a mean of 68 months of follow-up. ${ }^{18} \mathrm{An}$ important difference from our study was that the participants in the HARVEST study already had elevated clinic BP at baseline, and many began antihypertensive treatment over the course of follow-up.

In making the case of the potential clinical significance of our findings, we have assumed that the definition and prognosis of the nondipping pattern is the same in young, healthy, normotensive adults as in middle-aged, older, and/or hypertensive adults. An alternative assessment of our findings is that people who have optimal or near-optimal daytime BP do not exhibit a $10 \%$ nocturnal dip. In other words, it may be "normal" for people with optimal (or "low") daytime BP not to dip as much at night. Our interesting finding that average daytime BP among nondippers was actually lower than that of dippers while 24-hour averages were very similar between the two groups further supports this additional new hypothesis. One study previously demonstrated that even in normotensive individuals, the adjusted risk of cardiovascular mortality among nondippers is over twice that of dippers. ${ }^{6}$ However, average daytime BP in that study sample was $124 / 73 \mathrm{~mm} \mathrm{Hg}$ compared to the average of $117 / 70 \mathrm{~mm} \mathrm{Hg}$ in this study.

While our study had a reasonably long follow-up period over which to detect changes in clinical BP status, it was limited by a relatively small sample size and therefore may have been underpowered to detect a significant difference in prehypertension and hypertension rates. We must also acknowledge the possibility of misclassification bias in the measurement of nondipping status. Classifying patients into dippers or nondippers based on one ambulatory BP monitoring may be misleading and related to the quality of sleep the person experiences during the session. ${ }^{24}$ However, if misclassification bias did occur in this study, it would be nondifferential and cause the magnitude of association we found to actually be smaller than the true association. One study that used three ambulatory BP monitoring sessions to classify participants found that while associations with dipping status based on the initial session were somewhat weaker than associations based on all three, the patterns were similar. ${ }^{20}$

\section{Conclusions}

The nondipping BP pattern is common in young adults with normal BP (prehypertension as well as optimal BP). This finding has clinical significance because research to date has 
shown that nondipping is associated with cardiovascular target organ damage and mortality independent of elevated BP. Blacks, even at younger ages and when normotensive, have a higher prevalence than Whites of nondipping, a finding that may partially explain their greater hypertension-related morbidity. Nondipping might predate clinical hypertension in some people, but further studies with larger sample sizes are needed to clarify this hypothesis. More importantly, if it is shown in future studies that reduction of nocturnal BP in nondippers delays hypertension onset or leads to reduced target organ damage and cardiovascular disease events, more routine use of 24-hour ambulatory BP monitoring for screening would need to be considered.

\section{Acknowledgments}

The authors would like to thank Dr. Kirsten Bibbins-Domingo for her thoughtful review of an earlier version of this manuscript.

Financial Support: Dr. Viera's time to develop this article was supported by a career development award from the National Institutes of Health (KL2RR025746). The CARDIA study is funded by the CARDIA contract with NHLBI (N01-HC-48047 - N01-HC-48050 and N01-HC-95095).

\section{References}

1. Verdecchia P, Schillaci G, Guerrieri M, Gatteschi C, Benemio G, Boldrini F, et al. Circadian blood pressure changes and left ventricular hypertrophy in essential hypertension. Circulation. 1990; 81:528-536. [PubMed: 2137047]

2. Shimada K, Kawamoto A, Matsubayashi K, Nishinaga M, Kimura S, Ozawa T. Diurnal blood pressure variations and silent cerebrovascular damage in elderly patients with hypertension. J Hypertens. 1992; 10:875-878. [PubMed: 1325522]

3. Bianchi S, Bigazzi R, Baldari G, Sgherri G, Campese VM. Diurnal variations of blood pressure and microalbuminuria in essential hypertension. Am J Hypertens. 1994; 7:23-29. [PubMed: 8136107]

4. Verdecchia P, Porcellati C, Schillaci G, Borgioni C, Ciucci A, Battistelli M, et al. Ambulatory blood pressure: an independent predictor of prognosis in essential hypertension. Hypertens. 1994; 24:793801.

5. Fagard R, Celis H, Thijs L, Staessen JA, Clement DL, De Buyzere ML, et al. Daytime and nighttime blood pressure as predictors of death and cause-specific cardiovascular events in hypertension. Hypertens. 2008; 51:55-61.

6. Ohkubo T, Hozawa A, Yamaguchi J, Kikuya M, Ohmori K, Michimata M, et al. Prognostic significance of the nocturnal decline in blood pressure in individuals with and without high 24-h blood pressure: the Ohasama study. J Hypertens. 2002; 20:2183-89. [PubMed: 12409956]

7. Hoshide S, Kario K, Hoshide Y, Umeda Y, Hashimoto T, Kunii O, et al. Associations between nondipping of nocturnal blood pressure decrease and cardiovascular target organ damage in strictly selected community-dwelling normotensives. Am J Hypertens. 2003; 16:434-38. [PubMed: 12799090]

8. de la Sierra A, Redon J, Banegas JR, Segura J, Parati G, Gorostidi M, et al. Spanish Society of Hypertension Ambulatory Blood Pressure Monitoring Registry Investigators. Prevalence and factors associated with circadian blood pressure patterns in hypertensive patients. Hypertension. 2009; 53:466-72. [PubMed: 19171788]

9. Esler M. The sympathetic system and hypertension. Am J Hypertens. 2000; 13:99S-105S. [PubMed: 10921528]

10. Sayk F, Becker C, Teckentrup C, Fehm H, Struck J, Wellhoener JP, et al. To dip or not to dip: On the physiology of blood pressure decrease during nocturnal sleep in healthy humans. Hypertens. 2007; 49:1070-1076.

11. Friedman GD, Cutter GR, Donahue RP, Hughes GH, Hulley SB, Jacobs DR Jr, et al. CARDIA: study design, recruitment, and some characteristics of the examined subjects. J Clin Epidemiol. 1988; 41:1105-1116. [PubMed: 3204420] 
12. Knox SS, Hausdorff J, Markovitz JH. Reactivity as a predictor of subsequent blood pressureracial differences in the Coronary Artery Risk Development in Young Adults (CARDIA) Study. Hypertension. 2002; 40:914-919. [PubMed: 12468579]

13. White WB, Lund-Johansen P, McCabe EJ, Omvik P. Clinical evaluation of the Accutracker II ambulatory blood pressure monitor: assessment of performance in two countries and comparison with sphygmomanometry and intra-arterial blood pressure at rest and during exercise. J Hypertens. 1989; 7(12):967-75. [PubMed: 2628497]

14. Jacobs DR, Hahn L, Haskell WL, Pirie P, Sidney S. Validity and reliability of short physical activity history: CARDIA Study and the Minnesota Heart Health Program. J Cardiopulm Rehabil. 1989; 9:448-459.

15. Parikh NI, Pencina MJ, Wang TJ, Benjamin EJ, Lanier KJ, Levy D, et al. A risk score for predicting near-term incidence of hypertension: the Framingham Heart Study. Ann Intern Med. 2008; 148(2):102-10. 15. [PubMed: 18195335]

16. Roman MJ, Pickering TG, Schwartz JE, Cavallini MC, Pini R, Devereux RB. Is the absence of a normal nocturnal fall in blood pressure (nondipping) associated with cardiovascular target organ damage? J Hypertens. 1997; 15:969-978. [PubMed: 9321744]

17. Boggia J, Li Y, Thijs L, Hansen TW, Kikuya M, Bjorklund-Bodegard K, et al. Prognostic accuracy of day versus night ambulatory blood pressure: a cohort study. Lancet. 2007; 370:1219-1229. [PubMed: 17920917]

18. Palatini P, Mormino P, Mattarei M, de Venuto G, Graniero G, Laurini G, et al. Predictors of sustained hypertension in subjects with borderline to mild hypertension. A 5-year follow-up of the HARVEST study. Am J Hypertens. 2002; 4(Pt.2):27A. 15.

19. Manning G, Rushton L, Millar-Craig MW. Twenty-four hour ambulatory blood pressure: a sample from a normal British population. J Human Hypertens. 1998; 12:123-127. [PubMed: 9504353]

20. Spruill TM, Gerin W, Ogedegbe G, Burg M, Schwartz, Pickering TG. Socioeconomic and psychosocial factors mediate race differences in nocturnal blood pressure dipping. Am J Hypertens. 2009; 22:637-642. [PubMed: 19325537]

21. Profant J, Dimsdale JE. Race and diurnal blood pressure patterns. A review and meta-analysis. Hypertension. 1999; 33:1099-1104. [PubMed: 10334794]

22. Ferdinand KC, Saunders E. Hypertension-related morbidity and mortality in African Americanswhy we need to do better. J Clin Hypertens (Greenwich). 2006; 8(1 Suppl 1):21-30. [PubMed: 16415637]

23. Hinderliter AL, Blumenthal JA, Waugh R, Chilukuri M, Sherwood A. Ethnic differences in left ventricular structure: relations to hemodynamics and diurnal blood pressure variation. Am $\mathrm{J}$ Hypertens. 2004; 17:43-49. [PubMed: 14700511]

24. Manning G, Rushton L, Donnelly R, Millar-Craig MW. Variability of diurnal changes in ambulatory blood pressure and nocturnal dipping status in untreated hypertensive and normotensive subjects. Am J Hypertens. 2000; 13:1035-1038. [PubMed: 10981556] 
Table 1

Characteristics of Sample at Baseline (CARDIA Year 5) $(\mathrm{N}=264)$

\begin{tabular}{|c|c|}
\hline Age, mean (SD), y & $30.0(3.7)$ \\
\hline \multicolumn{2}{|l|}{ Age categories, $\%$} \\
\hline $23-29 y$ & 45.5 \\
\hline $30-36$ y & 54.5 \\
\hline Male, $\%$ & 45.1 \\
\hline \multicolumn{2}{|l|}{ Race categories, $\%$} \\
\hline White & 36.7 \\
\hline Black & 63.3 \\
\hline Education, mean (SD), y & $14.0(2.1)$ \\
\hline BMI, mean (SD) & $26.3(5.2)$ \\
\hline \multicolumn{2}{|l|}{ BMI categories, $\%$} \\
\hline Normal $\left(<25 \mathrm{~kg} / \mathrm{m}^{2}\right)$ & 44.7 \\
\hline Overweight $\left(25-29 \mathrm{~kg} / \mathrm{m}^{2}\right)$ & 30.7 \\
\hline Obese $\left(\geq 30 \mathrm{~kg} / \mathrm{m}^{2}\right)$ & 24.6 \\
\hline Known diabetes, $\%$ & 2.0 \\
\hline Family history of hypertension, $\%$ & 58.3 \\
\hline \multicolumn{2}{|l|}{ Smoker, $\%$} \\
\hline Never smoker & 62.5 \\
\hline Former smoker & 9.5 \\
\hline Current smoker & 28.0 \\
\hline Alcohol consumption, mL/day mean (SD) & $11.2(22.9)$ \\
\hline Physical activity, Kcal/Day, mean (SD) & $320.0(266.9)$ \\
\hline
\end{tabular}

BMI, body mass index 
Table 2

Blood Pressure Characteristics of Participants at Baseline (CARDIA year 5)

\begin{tabular}{lccc}
\hline & $\begin{array}{c}\text { Dippers } \\
(\mathbf{N = 1 4 6})\end{array}$ & $\begin{array}{c}\text { Non } \\
\text { Dippers (N=118) }\end{array}$ & p-value \\
\hline Characteristic & Mean \pm SD & Mean \pm SD & \\
Clinic BP & & & \\
SBP & $108.0(8.7)$ & $106.9(9.6)$ & 0.31 \\
DBP & $71.6(9.0)$ & $71.8(8.2)$ & 0.83 \\
Ambulatory BP & & & \\
24-h average SBP & $114.6(9.2)$ & $113.9(8.9)$ & 0.59 \\
24-h average DBP & $67.3(6.2)$ & $67.1(5.7)$ & 0.77 \\
Average daytime SBP & $118.3(9.6)$ & $115.2(8.9)$ & 0.008 \\
Average daytime DBP & $70.4(6.7)$ & $68.7(5.8)$ & 0.03 \\
Average nighttime SBP & $101.7(8.7)$ & $109.3(10.1)$ & $<0.0001$ \\
Average nighttime DBP & $56.8(6.1)$ & $62.0(7.3)$ & $<0.0001$ \\
Change in SBP, day - night & $16.6(3.9)$ & $5.9(5.1)$ & $<0.0001$ \\
Change in DBP, day - night & $13.6(4.6)$ & $6.7(5.6)$ & $<0.0001$ \\
\hline
\end{tabular}


Table 3

Characteristics Associated with Nondipping Status in Young Adults (CARDIA Year 5)

\begin{tabular}{|c|c|c|c|c|}
\hline & $\mathbf{n} / \mathbf{N}$ & Percent & Mean (SD) & p-value \\
\hline Age categories & & & & 0.51 \\
\hline $2329 \mathrm{y}$ & $51 / 120$ & 42.5 & & \\
\hline $3036 \mathrm{y}$ & $67 / 144$ & 46.5 & & \\
\hline Sex & & & & 0.65 \\
\hline Male & $55 / 119$ & 46.2 & & \\
\hline Female & $63 / 145$ & 43.5 & & \\
\hline Race & & & & 0.004 \\
\hline White & $32 / 97$ & 33.0 & & \\
\hline Black & $86 / 167$ & 51.5 & & \\
\hline Education level & & & & 0.89 \\
\hline$<$ High school & $5 / 12$ & 41.7 & & \\
\hline High school graduate & $37 / 79$ & 46.8 & & \\
\hline At least some college & $76 / 173$ & 43.9 & & \\
\hline BMI categories & & & & 0.07 \\
\hline Normal $\left(<25 \mathrm{~kg} / \mathrm{m}^{2}\right)$ & $48 / 118$ & 40.7 & & \\
\hline Overweight $\left(25-29 \mathrm{~kg} / \mathrm{m}^{2}\right)$ & $33 / 81$ & 40.7 & & \\
\hline Obese $\left(\geq 30 \mathrm{~kg} / \mathrm{m}^{2}\right)$ & $37 / 65$ & 56.9 & & \\
\hline Known diabetes & & & & 0.49 \\
\hline Yes & $3 / 5$ & 60.0 & & \\
\hline No & $115 / 259$ & 44.4 & & \\
\hline Family history of hypertension & & & & 0.97 \\
\hline Yes & $69 / 154$ & 44.8 & & \\
\hline No & $49 / 110$ & 44.6 & & \\
\hline Smoker & & & & 0.22 \\
\hline Never smoker & $69 / 165$ & 41.8 & & \\
\hline Former/current smoker & $49 / 99$ & 49.5 & & \\
\hline Alcohol consumption, mL/day & & & & 0.65 \\
\hline Nondippers $(\mathrm{n}=118)$ & - & - & $11.9(23.9)$ & \\
\hline Dippers $(\mathrm{n}=146)$ & - & - & $10.6(22.0)$ & \\
\hline Physical activity, Kcal/day & & & & 0.82 \\
\hline Nondippers $(\mathrm{n}=118)$ & - & - & $316.0(241.0)$ & \\
\hline Dippers $(n=146)$ & - & - & 323.3 (286.9) & \\
\hline
\end{tabular}

BMI, body mass index Dipper $=$ mean nighttime: mean daytime systolic BP ratio of $<0.90$;Nondipper $=$ mean nighttime:mean daytime systolic $\mathrm{BP}$ ratio $\geq 0.90$ 
Table 4

Incidences of Pre-Hypertension or Hypertension by Baseline Nocturnal BP Pattern (N=264)

\begin{tabular}{lccc}
\hline & Dippers & $\begin{array}{c}\text { Non-/Reverse } \\
\text { Dippers }\end{array}$ & p-value \\
\hline Crude & $64 / 146$ & $64 / 118$ & \\
No. of cases/Total & 29.2 & 36.2 & \\
Rate (No. per 1000 person-years) & 1.0 & 1.33 & 0.10 \\
HR (95\% CI) & & & \\
Race-adjusted & 1.0 & 1.22 & 0.27 \\
HR (95\% CI) & & & \\
Adjusted for race and BMI & 1.0 & 1.13 & 0.50 \\
HR ((95\% CI) & & & \\
Fully adjusted ** & & 1.15 & 0.45 \\
HR (95\% CI) & 1.0 &
\end{tabular}

HR, hazard ratio

Incident prehypertension was defined as clinic $\mathrm{BP} \geq 120 / 80 \mathrm{~mm} \mathrm{Hg}$. Incident hypertension was defined as clinic $\mathrm{BP} \geq 140 / 90 \mathrm{~mm} \mathrm{Hg}$ or taking antihypertensive medication at any of CARDIA years 7, 10, 15 or 20. Those taking BP meds or with a BP $\geq 140 / 90 \mathrm{~mm} \mathrm{Hg}$ at CARDIA year 5 (CARDIA Year 5 is baseline for this analysis) were excluded. An "event" occurred if a change in BP category was detected (optimal BP to prehypertension, prehypertension to hypertension, or optimal BP to hypertension).

***

Adjusted for age, sex, race, baseline clinic systolic BP, BMI, diabetes, family history of hypertension, smoking, alcohol intake, an physical activity 
Table 5

Incidence of Pre-Hypertension or Hypertension by Quartile of Baseline Mean Nighttime to Daytime Systolic BP Ratio (N=264)

\begin{tabular}{|c|c|c|}
\hline & HR & p-value \\
\hline \multicolumn{3}{|l|}{ Crude } \\
\hline Trend* & 1.12 & 0.10 \\
\hline Q1 & $1.00(\mathrm{ref})$ & \\
\hline Q2 & 1.20 & 0.50 \\
\hline Q3 & 1.38 & 0.20 \\
\hline Q4 & 1.61 & 0.06 \\
\hline \multicolumn{3}{|c|}{ Race-adjusted } \\
\hline Trend & 1.08 & 0.29 \\
\hline Q1 & 1.00 (ref) & \\
\hline Q2 & 1.14 & 0.63 \\
\hline Q3 & 1.24 & 0.42 \\
\hline Q4 & 1.43 & 0.71 \\
\hline \multicolumn{3}{|c|}{$\begin{array}{l}\text { Adjusted for race and } \\
\text { BMI }\end{array}$} \\
\hline Trend & 1.04 & 0.63 \\
\hline Q1 & $1.00(\mathrm{ref})$ & \\
\hline Q2 & 1.01 & 0.96 \\
\hline Q3 & 1.09 & 0.75 \\
\hline Q4 & 1.26 & 0.38 \\
\hline \multicolumn{3}{|c|}{ Multivariable-adjusted $^{* *}$} \\
\hline Trend & 1.05 & 0.48 \\
\hline Q1 & 1.00 (ref) & \\
\hline Q2 & 1.09 & 0.76 \\
\hline Q3 & 1.13 & 0.65 \\
\hline Q4 & 1.34 & 0.27 \\
\hline
\end{tabular}

HR, hazard ratio; ref, referent

An "event" occurred if a change in BP category was detected (optimal BP to prehypertension, prehypertension to hypertension, or optimal BP to hypertension).

Quartiles of mean nocturnal systolic BP/mean diurnal systolic BP ratio: Q1: 0.7360-0.8621 ( $\mathrm{n}=66)$; Q2: 0.8624-0.8926 ( $\mathrm{n}=66$ ); Q3: $0.8934-0.9385$ $(\mathrm{n}=66)$; Q4: $0.9388-1.1855(\mathrm{n}=66)$

P for trend based on continuous ratio variable

*** Adjusted for age, sex, race, BMI, diabetes, family history of hypertension, smoking, alcohol intake, physical activity, and baseline clinic systolic BP 